\title{
ANTROPOLOGÍA
}

\section{Rito funerario inverso. Terapia y valores}

\author{
Inverse funeral rite. Therapy and values
}

Exéquias revertida. Terapia e valores

\author{
Juan Carlos Delgado Antolín
}

Antropólogo. Enfermero de Atención Primaria C. S. de Griñón (MADRID).

Cómo citar este artículo en edición digital: Delgado Antolín, J.C. (2018). Rito funerario inverso. Terapia y

valores.Cultura de los Cuidados (Edición digital), 22(51). Recuperado de

<http://dx.doi.org/10.14198/cuid.2018.51.10>

Correspondencia: Juan Carlos Delgado Antolín C/ Villamanín 31 8 F 28011 Madrid.

Correo electrónico: jcdantolin@gmail.com

Recibido: 27/09/2017; Aceptado: 11/02/2018.

\section{ABSTRACT}

The funeral rite has a clear therapeutic component for the people who perform it, but when death is announced, the person who is going to die can perform what I have called a "reverse funeral rite." In this rite would produce a double therapeutic action: First for their loved ones helping them to overcome their loss and second for the individual himself to be able to face his own death. What may be the possible origin of this rite and the influence of culture and personal and community values on it.

Key word: Death, funeral rite, culture, values.

\section{RESUMEN}

El rito funerario tiene un claro componente terapéutico para las personas que lo realizan, pero cuando la muerte es anunciada, la persona que va a morir puede realizar lo que he dado en llamar un "rito funerario inverso". En ese rito se produciría una doble acción terapéutica: Primera para sus seres queridos ayudándoles a superar su pérdida y segunda para el propio individuo al poder enfrentarse a su propia muerte. Cuál puede ser el posible origen de este rito y la influencia de la cultura y los valores personales y comunitarios en él.

Palabras clave: Muerte, rito funerario, cultura, valores.

\section{RESUMO}

O rito funeral tem um componente terapêutico claro para as pessoas que fazem isso, mas quando a morte é anunciada, a pessoa que vai morrer pode fazer o que tenho chamado de "reverse rito funeral." Neste rito iria ocorrer uma acção terapêutica dupla: em primeiro lugar para os seus entes queridos ajudá-los a superar sua perda e segunda para o indivíduo a ser capaz de enfrentar sua própria morte em si. $\mathrm{O}$ que pode ser a possível origem deste rito ea influência da cultura e dos valores pessoais e comunitários na mesma.

Palavras-chave: Morte, rito fúnebre, cultura, valores. 


\section{INTRODUCCIÓN}

Cuando comencé a dar la asignatura de “Antropología de la muerte” en el máster de Cuidados Paliativos de la Universidad de Comillas en Ciempozuelos, se me ocurrió la "brillante" idea de hacer dos preguntas a los estudiantes antes de comenzar la clase. ¿Qué es para ti la muerte? ¿Qué le dirías a tus seres queridos si supieses que vas a morir? Si soy sincero, no sé a día de hoy lo que pretendía. Quizás ponerles en una situación hipotética ante su propia muerte, antes de darles mi asignatura y hablarles de la muerte y la relación bidireccional entre muerte y cultura; como hecho constitucional del ser humano y como refrendo de conocimientos del saber humano. Pero también quería realizar una investigación cualitativa sobre la importancia de los otros ante mi propia muerte, es decir, como podemos despedirnos de nuestros seres queridos si supiéramos que vamos a morir, si estamos ante una muerte anunciada por una enfermedad terminal o crónica prolongada.

Veamos algunos datos sociológicos de las personas que han asistido durante estos cinco cursos entre los años 2012 y 2016: el número total de asistentes han sido 67, lo que ha proporcionado una amplia documentación escrita sobre las dos preguntas planteadas. Como es obvio el alumnado era en su totalidad sanitario: 52 enfermeras 42 mujeres y 10 hombres, 8 médicos 6 mujeres y 2 hombres, 2 psicólogos 1 mujer y 1 hombre, y una matrona mujer. En total 52 mujeres y 15 hombres. La edad media era de 30,57 años, con un intervalo de 21 a 58 años y una moda de 23 entre los 2125 años. Esto planteaba que al ser una población joven, a priori no se habían planteado personalmente la pregunta de su propia muerte, pero por el contrario al ser una población sanitaria el enfrentamiento con la muerte es más cotidiano que en otras profesiones. Además el máster era de "Cuidados Paliativos" lo que también a priori presuponía un especial interés en cuidar $y$ ayudar a las personas con enfermedad en su fase final.

La primera pregunta no presentaba nada novedoso o inesperado. Mayoritariamente fue contestada como el final de la vida, el final de un proceso, la etapa final de la vida, y para algunos creyentes la unión con el ser supremo o la esperanza en la otra vida. Pero la segunda pregunta planteaba matices más variados, aunque se repetían palabras como: Gracias, amor, cariño, tranquilidad, agradecimiento, disculpa por lo que hayan podido hacer mal, consuelo, poder abrazarles, felicidad por haber podido compartir la vida con ellos, que aprovechen la vida. Pero también a algunos participantes les costaba situarse en ese determinado momento, y otros preferían reflexionar más profundamente sobre que decir para reconfortarles. Las personas con creencias religiosas expresaban dichas creencias y confiaban en poder encontrarse en la otra vida. También llamaba la atención, la aparición de un deseo que se repite con cierta frecuencia, diez veces, y aunque no llega a ser mayoritario, tiene su importancia. Es el deseo de que no se olviden de ellos cuando mueran. Para algunos, ese recuerdo es una forma de seguir vivos. Por último, algunas personas expresaban tímidamente el tipo de rito funerario que les gustaría recibir.

Veamos una muestra de algunos testimonios representativos de lo que se ha dicho.

"Que no me olviden, que sigan adelante con sus vidas pero teniéndome presente, sin sufrir.

A mi pareja, que este a disposición de rehacer su vida cuando esté preparado, de conocer a otra persona, pero que no me olvide.

Cuando este en fase terminal; que no me vean sufrir y que no me dejen sola en el proceso, que me cuiden” Mujer, 27 años.

“A la gente me gustaría decirle cuanto le quiero, gracias por haber compartido muchos momentos juntos y coincidir en esta vida.

Que me recuerden siempre, que me gustaría que donasen mis órganos (ya que no los voy a necesitar ahora que otros lo puedan aprovechar” Mujer, 22años.

“...y que cada vez que me recuerden sea con una sonrisa y que así moriré, cuando muera el último de mis amigos” Hombre.

“...Que representa el final de la vida y si es cristiano el comienzo de otra” Hombre.

"Que Jesucristo dijo "el que cree en mi aunque este muerto vivirá” Que crean en Jesucristo, que es el Camino, la Verdad, la Vida, no por obra 
sino por fe; él venció la Muerte” Mujer, 40 años.

"Reuniría a mi familia, los más cercanos, mi hermano y mi madre. Les daría las gracias. Gracias por haberme ayudado tanto en cada momento de mi vida. En esta vida tan dura que hemos vivido. Les daría las gracias por cada momento de alegría. Sobre todo les diría que estuvieran tranquilos porque yo estoy en paz. Tengo todo solucionado no me queda nada pendiente. Que no tengo miedo. Me están esperando los abuelos y mi otro hermano así que voy a estar bien allí.

$\mathrm{Y}$ que por favor ellos estuvieran tranquilos, porque yo estoy tranquila. Si ha llegado el momento es por algo. Será un tiempo separados pero luego todos nos volveremos a reunir" Mujer, 28 años.

"Les contaría a la gente que me quieren, que nuestra vida juntos se termina porque yo desaparezco de ella. Aprovecharía el tiempo que me quedara de vida al máximo con ellos para que tuvieran un buen recuerdo” Mujer, 27 años.

"La verdad que no lo tengo muy claro porque soy de pocas palabras y quizás expresaría mis sentimientos con abrazos y apretones de manos. Quizás diría gracias, gracias por haber estado conmigo durante el viaje de mi vida y gracias por estar ahora aquí conmigo. Y me gustaría decir que quedaran tranquilos, que yo me voy tranquila y sin sufrimiento” Mujer, 42 años.

“Llorad y reíd. No me olvidéis.

...tengo un archivo en el portátil que quizás queráis leer (quizás o me conocéis tanto o tan bien como creéis” Mujer, 21 años.

"1 Que no usen luto el día de mi entierro, vayan de blanco, con cosas rojas.

2 Que me velen con música suave, no en silencio.

3 Que si mis órganos sirven los den todos.

4 Que pronto nos volveremos a ver... si quieren encontrarme se porten bien.

5 que no estén tristes” Mujer, 33 años.

"La vida sigue. Recordadme. Reíd. En vuestros recuerdos viviré para siempre y la muerte no podrá matarme jamás” Hombre, 22 años.
"Yo les diría a mis seres queridos como quiero que me despidan. Morir en el hospital. Entierro. Funeral católico” Mujer, 35 años.

"Me cuesta pensar que no volveré a disfrutar de vuestra mirada, de vuestra presencia, de vuestra energía, por eso, os digo que os buscaré en el viento, en el agua, en el cielo. Es posible que ya no podamos disfrutar del contacto físico, pero nos queda el recuerdo de lo vivido, nos quedan las “ondas concéntricas” (estáis en mí y formo parte de vosotros, estamos interconectados, interrelacionados,...).

He vivido una vida plena. He experimentado el ser hija, el ser madre, el ser amiga, el ser esposa, el ser amante, compañera, discípula, maestra de otros..., me voy con la serenidad de haber experimentado y sentido el sonido de vuestras voces, de vuestros abrazos, de toda interacción... y también de haber podido disfrutar de lo que no se oye ni se toca (la apertura de una flor a lo largo del día, etc.) He viajado, he saboreado diferentes gastronomías, culturas, etc. Me voy plena, y con tanta gratitud. Os amo. Siempre” Mujer, 39 años.

Después de leer todos los testimonios, quedaba claro, que si tuvieran la oportunidad de poder despedirse, todos realizarían un esfuerzo por consolar, dar las gracias, y expresar su amor y cariño a sus seres queridos e incluso dejarían por escrito el rito que querían recibir en su despedida final. Se podría afirmar que antes de morir estaban realizando un claro rito funerario de antelación y que además tenía la cualidad de ser inverso, es decir, si el rito funerario es un acto social y cultural que llevan a cabo los vivos para con los muertos; en esta situación eran los futuros muertos los que realizaban en su despedida un rito de consuelo y de ayuda para sus familiares y amigos. Expresando en algunos casos un deseo de cómo querían ser despedidos, según sus propias preferencias.

Analicemos esa posibilidad

\section{Objetivo}

Muchos autores han trabajado sobre la importancia de los ritos de paso (Van Gennep, 2008) (Turner,1999) y dentro de los ritos de paso, los ritos funerarios (Ariès, 2005) (Varela, 1990) (Barley 1995), incluso yo he trabajo en ese mismo campo (Delgado Antolín, 2012), pero en todos no he encontrado, ni había 
profundizado en la posibilidad de realizar un ritual funerario anticipado y con doble funcionalidad, es decir, un rito funerario de las personas que van a morir, hacia las personas que van a seguir viviendo. Esa posibilidad de dejar un testimonio escrito de sus preferencias y sus deseos en los rituales funerarios que se realicen cuando él haya fallecido y sus posibles consecuencias; me parece un tema tentador para explorar, analizar su posible origen, su por qué y ver la influencia que en ello tiene tanto la cultura como los valores. Ese va a ser el objeto de la siguiente búsqueda y reflexión.

\section{Cultura y ritos}

Los seres humanos viven en sociedad y es dentro de este contexto donde se hacen humanos. Los humanos nacemos inacabados, nacemos demasiado pronto en comparación con otros primates, y aunque nuestra carga genética la tenemos desde el principio, ella por sí sola no es suficiente para llegar a ser humanos, nacemos con la condición de ser, pero tenemos que desarrollarlo a lo largo de un proceso (Savater, 1997). Por ello necesitamos vivir en sociedad y adquirir una cultura donde ejercer nuestra humanidad. Para ser humano en su totalidad, no sólo vale lo heredado, lo genético, lo innato; sino que la plenitud del desarrollo humano se encuentra en lo adquirido. El ser humano es el único ser vivo que se domestica a sí mismo mediante la cultura. Ese conocimiento adquirido se desarrolla, en un determinado contexto sociocultural donde se puede evolucionar al desarrollo pleno de la humanidad personal. Necesitamos del aprendizaje para socializarnos, aprender habilidades como el lenguaje, las formas, los modos y es ahí donde se produce la endoculturación de los individuos (Harris, 1994). Las generaciones precedentes tratan de formar a las futuras generaciones en la cultura a la que pertenecen: enseñando las leyendas, los conocimientos, las prácticas, los ritos, los valores y las normas.

Pero detengámonos en la importancia de ciertas prácticas, como son los ritos, y su importancia en la cultura a transmitir. Aunque el ritual y el rito son de difícil definición (González Varela, 2013), podemos decir que los ritos son actos sociales que se insertan dentro de la sociabilización de los individuos y en estos actos intervienen los individuos tanto de forma activa como pasiva. Normalmente en los ritos salvo los oficiantes e interesados, suelen ser intervenciones pasivas. Por los ritos se puede consolidar la estructura social, los lazos de unión con sus semejantes, con sus conciudadanos, con sus amigos y con sus familiares. Los ritos son elementos culturales que sirven para cohesionar y crear grupo. Al formar parte de la cultura, suelen ser una clara expresión de dicha cultura. Los ritos pueden ser de diversos tipos, simbólicos, religiosos, comunitarios,..., pero dentro de los llamados ritos comunitarios existen dos fundamentales.

"Los ritos comunitarios se agrupan en dos grandes categorías: 1) ritos de solidaridad y 2) ritos de paso: en los ritos de solidaridad, la participación en rituales públicos de carácter dramático realza el sentido de la identidad del grupo, coordina las acciones de sus miembros individuales y prepara al grupo para una acción de cooperación inmediata o futura. Los ritos de paso celebran el movimiento social de los individuos, entrando o saliendo de los grupos, accediendo o abandonando estatus de importancia crítica tanto para ellos como para la comunidad. En todo el mundo, los principales acontecimientos para la celebración de los ritos de paso son la reproducción, la llegada de la madurez, el matrimonio y la muerte" (Harris, 1994: 429-431)

Por último, y simplificándolo más, dentro de los ritos de paso, este concepto fue formulado por Van Gennep en 1909 (Van Gennep, 2008), tienen especial importancia y son a los que nos vamos a referir de ahora en adelante, los ritos funerarios.

\section{Ritos funerarios/El rito funerario inverso:}

Todos los ritos de paso son importantes para el protagonista, el nacimiento, la boda, etc., pues implican un cambio en su vida, pero también implican un cambio en los allegados. Al nacer una persona modifica las relaciones dentro del parentesco, convierte a sus progenitores en padres, a los padres de sus progenitores en abuelos, pueden existir ciertas personas que se conviertan en hermanos,... También mediante los ritos de paso, puede modificar las relaciones con sus amigos y compañeros, puede incorporar nuevas personas al entorno familiar $y$ de amistad, puede pasar a ser jefe o subordinado de un compañero anterior, etc. Todo rito de paso 
implica un cambio en las posiciones donde se produce y afectan tanto al protagonista del cambio como a las personas que rodean al protagonista.

En los ritos funerarios, es más claro, la importancia que tienen sobre los acompañantes, pues para la persona que ha fallecido su cambio es a la no existencia, siendo este un protagonista pasivo y convirtiéndose en una entidad ausente a pesar de su presencia en forma de cadáver durante el velatorio por ejemplo. Sin embargo para el resto de las personas que le rodeaban en vida y que en el fondo son los protagonistas del acto, pues son los organizadores de este ritual de despedida, van a experimentar un cambio de posición social y parental con su ausencia: viuda/o huérfana/o.

Los ritos funerarios tienen dos funciones principales: homenajear al difunto y una función terapéutica para los familiares y amigos del fallecido. Este último punto fue ya tratado por mí en "La fuerza terapéutica del rito funerario” (Delgado Antolín, 2005:49-53). Con la primera función está claro que lo que se pretende es dar un último rito de despedida a la persona fallecida. Despedirnos de la representación carnal que es su cadáver. Él ya no está, no es, pero queda el cuerpo que le albergó y merece una despedida digna. Ya sea mediante una ceremonia religiosa o laica, todo rito importante contiene un determinado tipo de ceremonia que le acompaña. Con la ceremonia ponemos punto final a su estar, no-estar. Nos despedimos de su cadáver y lo que representaba. Nos despedimos de su presencia en nuestras vidas.

Con la segunda función intentamos volver a la normalidad en nuestra vida y superar su pérdida, es decir, adaptarnos a su ausencia. Ausencia que a veces tiene nombre como ya se ha dicho: viudedad, orfandad, pero otras veces no posee un nombre concreto, como cuando se muere un hijo, un amigo, un novio o una novia, pero que representa una pérdida importante para la persona. Según esta segunda función, los ritos funerarios representan para los vivos, que los organizan y los presiden, unos ritos de paso. Porque con ellos se pretende superar su ausencia y recuperar cierta normalidad. Son ritos de paso porque hay un antes y un después. Antes, cuando estaba vivo y se tenía su compañía y después, cuando se tiene que seguir viviendo con su ausencia. Ausencia que va a ser permanente, pues sólo se va a tener su recuerdo, sus palabras, sus opiniones dadas en un momento concreto, pero ya se ha perdido la posibilidad de poder volver a verlo, a hablar con esa persona, ni a oír sus palabras y sus consejos. Estos ritos separan un antes y un después en nuestra vida, representando la fase liminal o marginal de los ritos de paso. Es la frontera entre su presencia y su ausencia. Seguir viviendo la pérdida definitiva del ser querido.

Hace unos años, cuando la cultura en este país era predominantemente religiosa y la normatividad de los ritos funerarios religiosos eran la “normalidad”. Los ritos eran eminentemente comunitarios, es decir, se realizaba de acuerdo a los valores que la sociedad donde se desarrollaban entendía por normal. El pensamiento único predominaba sobre el pensamiento plural y variado. Cuando alguien fallecía, se le velaba, se le hacia una misa de difuntos y se le enterraba en el cementerio. La normalidad estaba presidida por una normatividad establecida y encorsetada. Pero desde hace unos años los ritos funerarios han cambiado, han tenido variaciones aceptadas como una pluralidad válida: Presencia de tanatorios, la falta del color negro de luto, la elección de entierro o incineración, el depósito de las cenizas en columbarios o esparcidas por lugares agradables o habituales para el fallecido. Siendo quizás la más rupturista con la cultura anterior, la ausencia de funerales religiosos, que han sido sustituidos por otro tipo de funerales laicos, donde se dejan de lado los símbolos religiosos y son sustituidos por un simbolismo individual hacia la persona fallecida. En estos funerales se realiza un claro homenaje a su persona, a su recuerdo, a su ideas y sobre todo a su recuerdo.

Otro cambio importante ante la muerte en esta sociedad, ha sido el conocimiento de la proximidad de la muerte por la persona que va a fallecer. La información recibida sobre la enfermedad, la posibilidad de información en internet por parte de los pacientes, la presencia de los cuidados paliativos, etc. Este conocimiento de la realidad de su situación vital, ha posibilitado que muchas personas sepan cual es su esperanza de vida y puedan prepararse de alguna forma para su muerte y por lo tanto, para su despedida. También ha producido una angustia y una ansiedad ante esa presencia inminente o en un plazo pequeño de tiempo de 
su propia muerte. Pero para las personas que saben que van a morir y quieren despedirse de sus seres queridos, ha proporcionado tanto en los funerales laicos como en los religiosos, una nueva forma de rito funerario; donde la persona consciente de su pronto fallecimiento ha escrito una carta de despedida a sus seres queridos y amigos, ha dejado dicho que música quiere que se ponga en la despedida, incluso ha rodado un video, donde deja un documento con los momentos entrañables para él o las frases de consuelo para los que se quedan a este lado de la muerte.

Esta nueva forma de ritual programado, introduce una modificación en los ritos funerarios, que como ya he adelantado en la introducción, se podría llamar "rito funerario inverso". Pues en lugar de ser los vivos los que homenajean a los fallecidos, es la persona fallecida la que realiza un rito funerario para proporcionar paz y aliviar a sus allegados. Normalmente en estos ritos las personas que se han ido, tratan de aliviar. No ocurre lo mismo cuando en la lectura del testamento algunos familiares interesados, se encuentran con que el finado no les ha dejado nada, a pesar de lo que esperaban obtener. En estos ritos inversos las personas fallecidas dejan legados de gratitud, de felicidad sobre los momentos compartidos y vividos en conjunto. Con esas palabras tratan de aliviar la pena que puede dejar su ausencia. Quizás para aliviar también su propia despedida y transformar en cierta manera lo que puede ser un rito final, para él, en un rito de paso, también para él. Pues pasa de estar vivo a estar muerto y vive por unos momentos, aunque sea con la imaginación, lo que producirán sus palabras sobre las personas que quiere y estima. Por supuesto que esos escritos deben tener siempre destinatarios a los que se quiere. Lo mismo ocurre con los ritos funerarios cuando los realizamos para personas queridas por nosotros y no por puro compromiso social. Pero este enfrentamiento final a la muerte, también tiene otra función de tipo personal para la persona que va a morir. La persona que sabe que su final está próximo y tiene los días de vida contados, este rito funerario inverso, le produce un enfrentamiento a la idea de la muerte. ¿Qué es para esa persona la muerte y cómo afrontarla? Para cada uno de nosotros la muerte y su conceptualización es personal, pues dependerá de lo que hayamos vivido, sufrido, leído o experimentado. Cada uno ha transitado por la vida con una determinada idea de la muerte y esos momentos finales, nos enfrentarán a ella y a lo que representa, pudiendo salir de esa reflexión, de ese enfrentamiento final: tranquilos, tristes, amargados, aterrorizados,... y hay que tener cuidado, porque ese estado de ánimo lo vamos a poder transmitir a nuestros seres queridos.

Por lo tanto, el rito funerario inverso tiene también dos funciones. Primera, sirve para reflexionar sobre mi vida y mis relaciones con sus amores y sentimientos, y segunda servirá para dar consuelo a las personas que quiero y dejo al otro lado de la muerte. Ambas están interrelacionadas y ambas tienen una carga personal y sentimental importante.

El rito funerario inverso que se suele dar dentro de un funeral laico, también se puede realizar en un ritual religioso, y en lugar de escuchar las palabras del sacerdote sobre las virtudes de la persona que ha desaparecido, es el propio fallecido quien deja algo para los vivos. Cuando la persona que ha muerto quiere influir con sus palabras, con sus actos premeditados sobre el dolor y el pesar de los sus seres queridos cuando muera. Quiere influir de un modo terapéutico en su duelo. Intentando aliviar la pena de su desaparición para siempre, de su soledad perpetua.

\section{¿Cuál puede ser el origen?:}

Este tipo de funeral inverso que va tomando fuerza últimamente, puede deberse a un tipo de ritual importado, por ejemplo de las películas de Estados Unidos. En ellas podemos ver como los familiares y amigos del fallecido durante el funeral, normalmente en una iglesia, hablan de su vida en común y le recuerdan en su cotidianeidad $\mathrm{o}$ en algunos momentos compartidos donde se reflejaban rasgos de su personalidad. Aunque estas prácticas, con frases, conversaciones y anécdotas de la persona que ha fallecido, se tenían de una manera informar durante el velatorio con la familia en nuestra cultura, pero no se manifestaban de una forma pública. Como todos sabemos hay ciertas importaciones culturales, que suelen tener una gran difusión y aceptación en otras culturas y calan más profundamente que si son impuestas, es lo que se conoce por difusionismo, que Kroeber llamó “difusión por estimación” y que 
fue recogido por Leví-Strauss en su opúsculo "Papá Noel en la pira” (Levi Strauss, 1952) (Manguare, 2008). Son formas culturales que penetrar en otras culturas sin darse cuenta, adoptándolas por imitación y porque suelen tener buenos resultados en la práctica. Pero un verdadero ritual funerario inverso, que es al que nos referimos, lleva un paso más, es la persona fallecida quien toma el doble protagonismo, tanto activo como pasivo. Activo porque trata de aliviar a las personas que quiere su pérdida definitiva y pasivo, porque siendo el protagonista intelectual de lo que se realice en su funeral, no puede realizarlo él en su desarrollo práctico.

Pero también puede deberse a una transformación cultural desde los valores individuales y comunitarios.

Algunos antropólogos -Malinowski, Sperber- sostienen que muchos hechos culturales deben ser explicados en términos psicológicos, es decir, que los hechos culturales pasan por procesos mentales que los pueden transformar y adaptar a las situaciones concretas de la persona que los realiza y que a la vez los transmite. Así las representaciones culturales como prefiere llamarlas Sperber (Sperber 2005), pueden ser de dos tipos internas o "representaciones mentales" y externas que son las "representaciones públicas” (Sperber, 2005:15). Cuando contemplamos un hecho cultural, como es un determinado rito, lo vivimos y lo realizamos dentro de la cultura dominante a la que pertenecemos. Ello nos sirve para comprender que ese acto está admitido por dicha cultura como lo correcto, como ha mandado la tradición que debe hacerse. Pero a veces, cuando procesamos esos datos y los reelaboramos mentalmente buscamos transformaciones sobre esos ritos para que nos sirvan a nosotros. De ahí, que algunas veces digamos sobre determinadas formas de ritual, que no las vamos a realizar porque no sirven para nada, porque son una tontería, o porque ya no se llevan, es decir, determinados hechos culturales, determinados ritos, aunque son los adecuados como "representaciones públicas"; no son los adecuados como "representaciones mentales" o del ámbito privado. Siguen sirviendo para la comunidad, pero no nos sirven totalmente para nosotros. Por eso los intentamos transformar y modificar, para que nos sirvan tanto en su cometido público como privado. Muchas de esas transformaciones pueden deberse al cambio cultural que se ha dado en la sociedad actual. Pasando de una cultura única y monocromática a una cultura múltiple y multicromática. Esto no quiere decir que todos hayamos cambiado de cultura. Cada grupo cultural sigue elaborando sus ritos y sus costumbres dentro de un ámbito relativamente cerrado, pero es verdad, que con el aumento de las comunicaciones, con la inmigración sufrida en los últimos años, con la tan "cacareada” globalización que estamos padeciendo; nuestros ámbitos culturales se han podido ver influidos por otros ámbitos culturales.

Nuestra sociedad monocultural ha pasado a ser multicultural. Esa pluralidad cultural que se da en la sociedad actual y que nos ha abierto otras puertas, otras formas, otras representaciones rituales válidas para mi forma de ser o de pensar, es decir, para mi individualidad, es la que puede ir transformando mis preferencias y modificando de alguna manera mi jerarquía de los valores. Produciendo que el código único de paso a unos códigos múltiples, que son aceptados como "normalidad" dentro de la "normatividad" reinante. Por tanto, la autonomía personal y mis valores cada vez son más importantes a la hora de tomar decisiones tanto en la vida como en la muerte.

Los valores los utilizamos los seres humanos constantemente, son las realidades, las cosas, la acciones, que las personas tenemos por valiosas, por deseables y fundamentalmente tienen un componente de estima personal. Tratamos de darle un componente individual que mueve a las personas a promover los valores que le son apropiados, estimulantes y apetecibles. Los valores tratan de promover las actividades personales que me llevará a conseguir mis proyectos vitales. Nos movemos por valores y valoramos cotidianamente y continuamente, sin darnos cuenta. Nuestra vida está impregnada de valores aunque no lo percibamos. Afirma el profesor Diego Gracia:

“...La valoración es en el ser humano una necesidad natural, un fenómeno biológico. Sin valorar, nuestra vida sería imposible. Y ello por razones de estricta supervivencia. Valorar es una necesidad biológica tan primaria como percibir, recordar, imaginar o pensar. Nadie puede vivir sin valorar. De ahí el carácter primario de la noción de valor. Los valores son más básicos o elementales que las normas, las 
leyes o los principios de acción. Valoramos, porque no podemos no hacerlo. Todo es objeto de estima o de aprecio. La cosa más pequeña, un grano de arena, es objeto de aprecio o desprecio, y por tanto tiene al menos valor económico, es decir, precio” (Gracia, 2011: 17).

\section{Conclusiones:}

Los ritos funerarios tienen un claro valor terapéutico para la persona que lo realiza. Primero como homenaje de despedida al fallecido, y segundo como rito de paso para transitar desde su pérdida a la normalidad, es decir, para asumir la ausencia del fallecido y nuestra soledad.

La cultura es dinámica, pero a la vez es personal pues mi elaboración mental se encuentra contaminada de mis valores externos y mis valores internos desde los dos ámbitos desarrollo mi propia jerarquía de valores y realizo los ritos de acuerdo a ellos. De ahí, que el rito personal pueda integrarse dentro de la estandarización de los valores reinantes dentro de ese determinado grupo. $\mathrm{Y}$ cuando nos referimos a la cultura de un determinado grupo humano, entendemos que son las manifestaciones que pueden ser comprobables, porque todos los miembros de ese grupo las realizan con una determinada unanimidad, y son conocidas y reconocidas por propios y extraños. Ej. El rito funerario en la cultura hindú es la incineración y en la cultura islámica es el enterramiento.

Pero últimamente dentro de los ritos funerarios, va tomando fuerza lo que se he dado en llamar ritual funerario inverso, donde la persona que va a fallecer interviene activamente en ese rito futuro que va a ser su funeral. Con ello trata de consolar y ayudar a sus seres queridos para superar su pérdida, y a la vez, le sirve a él para prepararse, en cierta forma, para su muerte. Alcanzando con ello un doble fin terapéutico para él y para sus allegados. Son decisiones personales que tratan de aliviar la muerte en ambos dominios.

Este hecho donde valores tradicionales y de la comunidad pueden verse modificados por valores personales de preferencia, deben integrarse dentro de una determinada normalidad establecida para que sean válidos para todos. Aplicando la normatividad y la normalidad como un continuum, es decir, siguiendo mínimamente las normas para llegar a nuestra normalidad personal. Afortunadamente los códigos ahora son más plurales.

El mundo es cada vez más pequeño, más estrecho, el difusionismo es cada vez más frecuente y las ideas que antes pasarían inadvertidas, ahora tienen o pueden tener cierta influencia y consideración. Por eso debemos tener más cuidado cuando se trata de "pescar" pensamientos y reflexiones en el mundo de las ideas y de las opiniones. No todo sirve y lo que es bueno para uno, puede no tener valor para otro. La guía son nuestros valores, tanto los personales como los comunales y la reflexión y el respeto pueden ser el camino.

\section{BIBLIOGRAFÍA}

Ariès, P. (2005). Historia de la muerte en occidente: Desde la Edad Media hasta nuestros días. Barcelona: El Acantilado.

Barley, N. (2000). Bailando sobre la tumba. Barcelona: Anagrama.

Delgado Antolín, J. C. (2012). La muerte desde la cultura y para la cultura. Madrid: Exlibris.

Delgado Antolín, J.C.s (2005). La fuerza terapéutica del rito funerario. Cultura de los Cuidados, 17, 49-53.

Gracia Guillén, D. (2011). La cuestión del valor. Discurso de ingreso a la Real Academia de Ciencias Morales y Políticas de España. Madrid: Real Academia de Ciencias Morales y Políticas.

González Varela, S. (2013). Mito, experiencia y práctica: Relacionalidad y recursividad en el estudio antropológico del ritual. Revista de Antropología Experimenta, 13(23), 381-397.

Harris, M. (1994). Antropología Cultural. Madrid: Alianza Editorial, Madrid.

Leví-Strauss, C. (2008). Papá Noel en la pira. Maguare, 22, 21-42.

Savater, F. (1997). El valor de educar. Barcelona: Ariel.

Sperber, D. (2005). Explicar la cultura, un enfoque naturalista. Madrid: Ediciones Morata. Turner, V. (1999). La selva de los símbolos. Madrid: Siglo XXI.

Van Gennep, A. (2008). Los ritos de paso. Madrid: Alianza Editorial.

Varela, J. (1990). La muerte del rey: El Ceremonial funerario de la monarquía (15001885). Madrid: Turner española. 